\title{
COMUNICAÇÃO ALTERNATIVA NA EDUCAÇÃO INFANTIL: NOVAS PRÁTICAS PEDAGÓGICAS
}

\section{Patrícia Celis Murillio}

Leandro Osni Zaniolo

Universidade Estadual Paulista

\section{Resumo:}

A Comunicação Alternativa (CA) introduz uma nova prática pedagógica ao entender que o processo linguístico não precisa ser dado por uma linguagem oral. No entanto, as práticas escolares reconhecem na linguagem oral 0 principal meio de comunicação. $\mathrm{O}$ objetivo da pesquisa consistiu em descrever a realidade da educação infantil inclusiva para crianças que não falam. Esta pesquisa é um ensaio bibliográfico sobre a efetividade da CA na educação infantil, mediada por leis e portarias que regulamentam as ações educacionais inclusivas. Resultados: $\mathrm{O}$ universo escolar, da educação básica, encontra na estrutura curricular e na formação continuada dos professores, um descompasso frente às necessidades emergentes da educação inclusiva. Contudo, a prática da comunicação alternativa vem sendo gradualmente inserida nas escolas da educação básica junto aos grupos de pesquisa.

Palavra Chaves: Educação infantil; educação inclusiva; comunicação alternativa. 


\title{
ALTERNATIVE COMMUNICATION IN EARLY: CHILDHOOD EDUCATION: NEW PEDAGOGICAL PRACTICES
}

\begin{abstract}
Summary: The communication alternative (CA) introduces a new pedagogical practice to understand the linguistic process does not need to be given by an oral language. However, school practices recognize oral language is the main means of communication. The goal of the research was to describe the reality of inclusive early childhood education for children who do not speak. This research is a bibliographic essay on the effectiveness of the CA in early childhood education, mediated by and laws and ordinances governing educational actions. Results: the universe of basic education school located on the curricular structure and the continuous formation of teachers, a gap against the emerging needs of inclusive education. However, the practice of alternative communication is being gradually inserted in schools of basic education among the research groups.
\end{abstract}

Word Keys: Early childhood education; inclusive education; alternative communication. 


\section{Educação como Direito: Educação Infantil uma retrospectiva histórica}

A educação infantil surgiu da articulação entre os interesses jurídicos, políticos, médicos, pedagógicos e religiosos, do início do século XX, que determinaram diferentes influências sobre a educação (ANDRADE, 2010).

Podemos dizer que o que diferencia o Brasil dos países da Europa está no fato de que as creches, no Brasil, surgiram para minimizar problemas sociais decorrentes da miséria, ao contrário da Europa que a expansão das creches se deu devido ao recrutamento das mulheres como mão de obra para as fábricas.

A origem das creches no Brasil, no início do século $\mathrm{XX}$, revela antecedentes que são vinculados às instituições asilares destinada aos filhos carentes de mães solteiras e viúvas, em condições de internato. Certamente, as origens do ensino infantil, atrelada ao desenvolvimento da industrialização, aponta uma sociedade com anseios capitalistas que emergia para uma vida urbanizada, mas, sofria com as epidemias decorrentes de um problema de saúde coletivo.

A educação infantil passa a ser uma estratégica de saúde pública que tinha a educação básica como recurso pedagógico para disciplinar os corpos e instruí-los a novos hábitos. $\mathrm{O}$ atendimento nas creches, vinculado à esfera médica e sanitarista, tinha como objetivo promover a saúde e difundir normas rígidas de higiene associando à pobreza a falta de conhecimentos, negando as questões econômicas e políticas do país (ANDRADE, 2010; SCHEIB, 2010).

As políticas públicas, da década de 1930, refletem os diferentes interesses da burguesia, dos trabalhadores, e do Estado. Assim, houve a criação do Ministério da Educação e Saúde assumindo oficialmente a responsabilidade pelo atendimento a infância. Dessa forma, desde 1930 a educação infantil tinha cunho assistencial e educativo pedagógico.

Olh@res, Guarulhos, v. 3, n. 1, p. 122-142. Maio, 2015. 
No ano de 1941 foi criada a legião Brasileira de Assistência (LBA) e as políticas voltadas para a infância, no Estado Novo, configuraram a proteção da criança de 0 a 6 anos. O golpe militar de 1964 acarretou profundas mudanças marcadas pela repressão da ação governamental destinada às crianças e adolescentes. Após a ditadura militar a explosão de movimentos sociais no país em prol a abertura democrática leva a um cenário de grande mobilização em 1980, em torno dos direitos humanos, resultando em um novo ordenamento legal e uma nova doutrina que culmina em 1988 com a promulgação da Constituição Brasileira (ANDRADE, 2010; SCHEIB, 2010).

A visibilidade da Educação Especial vem a acontecer mediante a esta série de acontecimentos sociais que vieram a culminar com a constituição de 1988, proclamando a Educação como um direito de Todos e dever do Estado. Em 1990, o Brasil concorda com um sistema de educação inclusivo, com a Declaração de Educação Mundial de Educação para Todos, na conferência mundial da UNESCO, realizada na Tailândia. Essa nova ideologia é reafirmada com a Declaração de Salamanca na ação na área das Necessidades Educativas Especiais, UNESCO 1994 (CURY, 2008; SEKKEL \& MATOS, 2011).

Desde então o país instalou um processo de transformação no sistema educacional brasileiro, que teve como desdobramento mudanças na legislação e na elaboração das diretrizes nacionais para a educação, todas elas norteadas pela ideia da educação inclusiva. A Lei de Diretrizes e Bases da Educação Nacional - LDB 9394/96, os Parâmetros Curriculares Nacionais - Adaptações Curriculares: estratégias para a educação de alunos com necessidades educacionais especiais, em 1998, e as Diretrizes para a Educação Especial na Educação Básica, em 2001, entre outras (PIMENTEL, 2012; SEKKEL \& MATOS, 2011).

De acordo com a LDB (Lei de Diretrizes e Bases, 1996). 


\section{Capitulo V \\ Da Educação Especial.}

Art. 58. Entende-se por educação especial para efeitos desta Lei, a modalidade de educação escolar, oferecida preferencialmente na rede regular de ensino, para portadores de necessidades especiais

$1^{\circ}$. Haverá quando necessário, serviços de apoio especializado na escola regular, para atender as peculiaridades da clientela de educação especial.

$2^{\circ}$. O atendimento educacional será feito em classes, escolas ou serviços especializados, sempre que, em função das condições específicas dos alunos, não for possível a sua integração nas classes comuns de ensino regular.

$3^{\circ}$. A oferta de educação especial, dever constitucional do estado, tem início na faixa etária de 0 a 6 anos, durante a educação infantil

Art. $59^{\circ}$. Os sistemas de ensino assegurarão os educandos com necessidades especiais

I - currículos, métodos, técnicas, recursos educativos e organização específica, para atender às suas necessidades.

III - professoras com especialização adequada em nível médio ou superior, para atendimento especializado, bem como professores do ensino regular capacitados para a integração desses educandos nas classes comuns BRASIL (2014, p. 33).

A política de formação de professores para inclusão de estudantes com deficiência é preconizada desde a Lei de Diretrizes e Bases da Educação Nacional - LDB n.9.394/96 que define que os órgãos governamentais devem assegurar aos professores capacitações que viabilizem uma educação com qualidade, com currículos, métodos, 
técnicas e recursos educativos que atendam às necessidades destes educandos (PIMENTEL, 2012).

De acordo com os Parâmetros Curriculares Nacionais (Brasil1998), para que haja de fato a implementação do modelo de atuação inclusiva são requeridas a modificação e superação de obstáculos oferecidos pelo sistema de ensino regular, de sorte que a capacitação docente deve ser vista como uma das metas do sistema educacional a fim de que ocorra a inclusão de direito e fato (SAMESHIME 2009, p. 32).

De acordo com Pimentel (2012), após 16 anos da promulgação desta lei, os professores da escola básica se encontram despreparados para o trabalho com estudantes com deficiência.

A ausência de conhecimento do professor sobre as peculiaridades das deficiências, o não reconhecimento das potencialidades destes estudantes e a não flexibilização do currículo podem ser considerados fatores determinantes para barreiras atitudinais, práticas pedagógicas distanciadas das necessidades reais dos educandos e resistência com relação à inclusão (PIMENTEL, 2012, p.140).

Fica claro que não basta garantir o acesso destes estudantes à escola regular, é necessário o apoio ao docente para que esta inclusão ocorra de fato, garantindo a equidade no atendimento pedagógico, assim a formação docente deve envolver a compreensão da diversidade na realidade de cada sujeito (GATTI \& BARRETO \& ANDRÉ, 2011).

Para tanto, a ação pedagógica numa escola inclusiva deve requerer do professor subsídios teóricos e metodológicos para buscar novas formas de ensinar, de modo que possa efetivar um processo de aprendizagem. Isto requer um investimento constante em práticas investigativas, buscando referenciais teóricos e epistemológicos que favoreçam a compreensão da aprendizagem, para cada aluno em singular. A inclusão reestrutura o sistema de ensino, com o objetivo de fazer com que a escola se torne aberta ás diferenças (GATTI \& BARRETO \& ANDRÉ, 
O governo chamou para si a incumbência de formular referências curriculares capazes de consolidar a concepção de educação básica como um processo contínuo. A reforma curricular é uma peça chave fundamental para a reforma na mudança de eixo das políticas de igualdade voltada para todos. A educação como direito humano se impõe também como direito a diferença o que demanda profundas transformações no conjunto dos padrões de relacionamento da sociedade (GATTI \& BARRETO \& ANDRÉ, 2011).

O objetivo da pesquisa consiste em descrever a importância da linguagem e da comunicação buscando difundir a Comunicação Alternativa como proposta pedagógica para crianças que não oralizam, e que estão inseridas no contexto inclusivo da Educação Infantil. Neste sentido, vamos demonstrar a atual conjuntura, expressa por uma educação política nacional de inclusão, que solidifica a educação como direito de todos. Assim, a pesquisa buscou seus alicerces em referenciais teóricos que pudessem traduzir a construção do processo para uma Comunicação Alternativa, na primeira infância, na sua inter-relação com a deficiência da oralidade e a realidade da escola inclusiva.

\section{Caminhos Metodológicos:}

A pesquisa teve inicio a partir de uma disciplina realizada na pósgraduação, UNESP-Araraquara, na área de Educação Escolar no ano de 2014. A disciplina tinha como objetivo demonstrar a Comunicação Alternativa como meio para uma Comunicação social das crianças que não oralizam. A importância do tema me remeteu a uma busca bibliográfica sobre a perspectiva da Comunicação Alternativa na Educação Infantil Inclusiva.

A busca bibliográfica foi realizada no SCIELO e junto aos referencias bibliográficos obtidos durante o decorrer da disciplina. A pesquisa destinou-se a contextualizar a Educação infantil como um direito de Olh@res, Guarulhos, v. 3, n. 1, p. 122-142. Maio, 2015. 
todos, realizando uma busca ativa do histórico da educação infantil e suas correlações com a Educação Inclusiva na questão da linguagem, análise da LDB e dos PNE ressaltando os direitos das pessoas com deficiências e levantamento de dados referentes à formação docente e estrutura curricular para uma Educação Inclusiva.

\section{Pensamento e Linguagem: O lugar do outro na educação}

Para uma maior compreensão vamos definir língua e linguagem antes de avançarmos para a questão epistemológica do pensamento. Assim, a língua é um conjunto de normas e regras fixas, estruturada pela gramática. Língua como um sistema de possibilidades que oferece um conjunto flexível de regras de seleção de combinação e substituição sem comprometer ou alterar a interação. Cada língua possui suas particularidades e seus signos linguísticos (VON TEZCHNER, 2005; DELIBERATO, 2009; MORESCHI \& ALMEIDA, 2012).

A linguagem, no entanto, é um fenômeno humano relacionado com as práticas sociais e a capacidade de poder se comunicar por meio dela, conseguindo manifestar; sentimentos, emoções e pensamentos; sendo a linguagem um instrumento de comunicação e interação com o outro. A linguagem é o centro de interesse de vários campos de estudo desde a linguística até a neurobiologia, e entende-se que a linguagem está envolvida com funções mentais superiores, logo o indivíduo apresenta um substrato orgânico com vários sistemas interligados que se relacionam com o meio e assim produzem conhecimento (DELIBERATO, 2009).

Fala, escrita, expressão corporal e gestos são formas de comportamento que os indivíduos possuem para expressar a sua linguagem interna. A comunicação, no entanto, consiste em poder compreender o que o indivíduo quer dizer ou fazer-se entender pelo interlocutor (DELIBERATO, 2009). 
Pensar a ação do outro na aquisição da linguagem traz ao contexto atual um apartamento das teorias inatistas e uma aproximação com as teorias interacionistas, onde a linguagem não é uma função inata ou apenas de ordem genética, ou melhor, a linguagem é um arcabouço de representações simbólicas com diferentes formas que se expressam por meio de signos, a língua. A constituição social e cultural da linguagem corrobora com o entendimento de que a aquisição da linguagem também necessita do outro para o seu desenvolvimento (PEREIRA, 2012).

Entendemos que o pensamento constitui-se por uma construção social/cultural e histórica e a sua representação simbólica pode ser expressa via linguagem, ou seja, pode ser partilhada com o outro mediante um meio de comunicação verbal ou não verbal. No caso das crianças que não oralizam, podemos inferir que a linguagem interna está presente, mas sua expressão verbal se encontra tolhida (PEREIRA, 2012).

Quando apontamos o outro como uma necessidade para o desenvolvimento da linguagem das crianças normais, esta mesma perspectiva também é necessária para as crianças que não oralizam. A linguagem interna das crianças, que não oralizam, pode encontrar novos caminhos, além da oralidade, sendo projetada para um método de ensino inclusor, que as possibilite comunicação (AZENHA, 2005).

Os rumos educacionais dados para uma inclusão efetiva apontam a Comunicação Alternativa como um instrumento que pode transitar entre o pensamento e a linguagem da criança que não oraliza, modificando uma realidade ao permitir que o desenvolvimento infantil venha a ser respaldado por uma comunicação que o interaja com o seu convívio social (VON TETZCHNER, 2005).

Comunicação Alternativa e Inclusão Escolar Olh@res, Guarulhos, v. 3, n. 1, p. 122-142. Maio, 2015. 
A Comunicação Alternativa e Suplementar tem ampliado os seus locais de atuação, saindo das clínicas e instituições especializadas para abranger serviços da secretaria de educação e secretaria de saúde das prefeituras municipais. Não é possível negar o papel que as instituições especializadas tiveram na produção de conhecimentos a cerca de metodologias de trabalho com pessoas com necessidades especiais diante das políticas de inclusão (CARNEVALE et al, 2013).

No processo de interação, entre a criança e os seus interlocutores, ocorre à formação de conceitos levando-as a capacidade de simbolizar o mundo que as cerca por meio das expressões verbais ou não verbais. A linguagem falada assume o principal meio de comunicação, para o processo de ensino e aprendizagem das crianças na educação infantil.

Os sistemas não verbais de comunicação são todos aqueles que proporcionam a expressão funcional através dos símbolos distintos de quem se comunica, podendo ser classificado em dois grupos distintos: Sistemas de comunicação com apoio e sistemas de comunicação não apoiado.

Os sistemas de comunicação não apoiados são aqueles que não necessitam de nenhum instrumento ou meios auxiliares utilizando-se de gestos comuns, códigos gestuais, sistema de línguas de sinais, alfabeto manual. Os sistemas apoiados, no entanto, utilizam elementos representativos como objetos, fotos, figuras, pictogramas e sistemas que combinam símbolos pictográficos e ideográficos.

Quanto às terminologias, Comunicação alternativa (CA); Comunicação Suplementar Alternativa (CSA); Comunicação Ampliada (CA) ou Comunicação Facilitadora (CF) tais termos carregam conotações e sentidos diferentes em função da área de conhecimento e do referencial teórico adotado, não havendo em dias atuais um consenso para o uso desta terminologia (CHUN, 2009). 
A expressão Augmentativa and Alternative Communication (AAC), traz a conotação de auxiliar, servir de apoio, complementar, enfim suplementar a comunicação dos outros meios já empregados como gesto, olhar, expressão facial, sorriso, além da própria fala ou vocalização que pode estar presente. Esta expressão deve ser empregada quando claramente se acrescenta um meio a fala natural, caracterizando uma substituição da fala ou da escrita (CHUN, 2009).

As denominações Comunicação Alternativa, Comunicação Ampliada ou Suplementar vem ao encontro de uma comunicação diferente da tradicional, fazendo uso de símbolos pictográficos, ideográficos e arbitrários. A comunicação alternativa não tem como objetivo substituir a linguagem oral, mas constituir-se em um instrumento para atingi-la (DELIBERATO, 2009).

A Comunicação Alternativa é uma das áreas da Tecnologia Assistida (TA) que tem o objetivo de promover habilidades de pessoas com limitações funcionais decorrentes de diferentes deficiências. A CA visa a compensar e facilitar de forma temporária ou permanente as limitações e os padrões de inabilidade de indivíduos com transtornos expressivos da compreensão da linguagem falada ou escrita (CARNEVALE et al, 2013; CESA \& SOUZA, 2010).

Nos sistemas simbólicos, não apoiados, o aluno utiliza apenas o próprio corpo para se comunicar já os sistemas simbólicos, apoiados, requerem instrumentos além do corpo do aluno para produzir uma mensagem. Estes sistemas podem ser simples e de baixa tecnologia como objetos concretos e símbolos gráficos organizados em pranchas de comunicação ou sistemas de alta tecnologia que incluem os sistemas simbólicos apresentados em comunicadores pessoais ou computadores (CARNEVALE et al, 2013).

A proposta pedagógica para uma Comunicação Alternativa tem três momentos específicos: escolha dos recursos, estratégias e técnicas. Os recursos são dispositivos utilizados para transmitir as mensagens como: pranchas, dispositivos eletrônicos, comunicadores, tabletes, Olh@res, Guarulhos, v. 3, n. 1, p. 122-142. Maio, 2015. 
computadores. As estratégias compreendem o modo como os recursos serão empregados e a técnica é a forma com o usuário da CA fará a seleção dos símbolos (ALMEIDA \& PIZA \& LAMÔNICA, 2005; MORESCHI \& ALMEIDA, 2012).

Dentro da comunicação alternativa podemos encontrar três recursos importantes como:

1- Sistema de comunicação por intermédio de figuras (PECS), descrito por Frost e Bondy em 1996. Pessoas sem comunicação oral são ensinadas a utilizar figuras representativas de objetos, situações, sentimentos. O processo ocorre basicamente por meio da troca de figura.

2- Sistema Picture Communicacion Symbols (PCS) proposto por Johson (1980-1998), composto por 3.000 mil figuras que expressam uma grande variedade de palavras, situações de vida diária e prática. O PCS é um sistema gráfico visual que contém desenho simples podendo acrescentar, na medida do necessário, fotografias, figuras, números, circulo para cores, o alfabeto, outros desenhos ou conjuntos de símbolos.

3 - Sistema Bliss, criado por Charles K. Bliss (1942-1965) é um sistema suplementar e ou alternativo da comunicação, constituindo-se em um sistema simbólico gráfico visual, composto por símbolos feitos de formas geográficas, que representam conceitos simples ou complexos. A pesar de sua vasta possibilidade de comunicações, a sua aprendizagem é mais lenta e exige maior desempenho cognitivo.

O Bliss é um sistema dinâmico capaz de representar conceitos abstratos e há varias formas de se expressar através dele por meio de frases simples ou complexas que utilizam uma quantidade básica de formas geométricas e seus segmentos. A Blissymbolics Communications internacional criou réguas - matrizes, conforme o tamanho do símbolo para realização de confecções dos desenhos. 
A literatura tem discutido a importância de alguns cuidados na seleção de recursos alternativos e ou suplementares pensando em inserir um contexto de comunicação funcional. Também devemos dar importância aos procedimentos empregados durante a utilização da CA como o planejamento do tamanho, cor, disposição de figuras. Para a seleção dos recursos alternativos são necessários cuidados com a confecção de um tabuleiro de figuras e na seleção de palavras.

De acordo com Deliberato 2009; Vita, 2010; Cesa \& Souza 2010, a carência de conhecimento por parte dos professores a cerca dos recursos e procedimentos alternativos de comunicação merece uma atenção especial. Contudo a educação infantil, alvo da inclusão, é importante não só para atender a inclusão da criança que não oraliza como também promover o seu desenvolvimento e prevenir déficits funcionais.

Para Vita (2010), Carnevale et al, (2013), Sekkel e Matos (2011) a formação de professores precisa ser considerada temporalmente, no atual contexto socio-histórico que vivemos, pois a simples presença de uma TA, direcionada para CA, não torna as escolas mais inclusivas se tais recursos não atuam em prol do ensino e aprendizagem.

Para Carnevale et al (2013) e Vita (2010) a comunicação ainda se dá basicamente na leitura que os professores fazem dos choros das expressões faciais e demais manifestações de seus alunos, sem a utilização sistematizada dos recursos existentes para CA. Consequentemente, alunos sem fala permanecem na condição de seres falados a partir de uma leitura governada primordialmente pelo imaginário de quem o interpreta.

Algumas contribuições sobre o papel da fala no processo dito formal pode contribuir para o entendimento das dificuldades encontradas por professores e alunos quando a fala está ausente, pois a fala é a modalidade da linguagem priorizada na maioria das relações sociais inclusive no ambiente escolar. A oralidade ainda é para o universo 
escolar meio de transmissão para a construção de conhecimentos (ZUCHETTI, 2011; CARNEVALE et al, 2013).

\begin{abstract}
Pesquisas apontam que os professores do ensino regular não possuem capacitação adequada e, muitas vezes pode encontrar dificuldades em lidar com o aluno com deficiência com a falta de conhecimentos teóricos e práticos para lidar com essa população, o professor encontra dificuldades para organizar um bom planejamento pedagógico, adaptar recursos e estratégias, a fim de possibilitar o entendimento, a realização e a participação efetiva do aluno com deficiência, nas atividades pedagógicas (SAMESHIMA, 2009 p.19).
\end{abstract}

A comunicação Alternativa, portanto, possibilita uma ruptura com um cenário de ações e de concepções corriqueiras como: não falar estar associado a não poder se manifestar suas escolhas. (CARNEVALE, 2013; SEKKEL \& MATOS, 2011).

A oralidade, enquanto meio prioritário da comunicação para o ensino e aprendizagem, associada ao peso do estatuto do universo escolar parece responder pelas dificuldades que professores do ensino básico apresentam durante o processo de alfabetização de crianças que não oralizam (PAULA \& ENUMO, 2007; CARNEVALE et al, 2013).

Para Sameshima (2009) muitos estudos apontam o papel do fonoaudiólogo como urgente para a formação de profissionais, do âmbito escolar, para que assumam tarefas anteriormente exclusivas da fonoaudióloga. Encontra-se a necessidade de orientar e auxiliar todos os membros da escola como professores, diretores, coordenadores. Assim, a fonoaudiologia trabalha em prol da inclusão interligando a criança a escola e a família.

A família também é um ambiente apontando por diferentes autores como meio de expansão para o ensino, aprendizagem $\mathrm{e}$ desenvolvimento, possibilitando a mediação da comunicação desta criança. O papel da escola, da família e a atuação de professores e fonoaudiólogos junto às crianças, que não oralizam, percorrem caminhos ainda desconhecidos que certamente levam a necessidade 
urgente de um currículo adaptado. Um currículo próximo dos anseios educacionais de uma criança em desenvolvimento.

\section{Considerações Finais}

Observa-se que nunca, em toda história, se estudou tanto sobre a educação de pessoas com deficiência como o século atual. (ZOBOLI, 2009). A necessidade de incluir pessoas com deficiência no ensino regular, por meio da Comunicação Alternativa, reflete uma nova proposta pedagógica que vem a subsidiar a educação básica, suplantando a fala por recursos não verbais e gestuais (SAMESHIMA, 2009; ZOBOLI, 2009).

A Educação Infantil passa por um momento de reflexão de seus componentes ideológicos e organizacionais incorporando à sua história a inclusão da criança com necessidades especiais. As mudanças na legislação e na elaboração das diretrizes nacionais para a educação, norteadas pela ideia da educação inclusiva, ainda estão sendo organizadas no Brasil.

Os direitos estabelecidos por uma política nacional de inclusão garantindo ao aluno o direito pleno de cursar todo o ensino básico com todo e qualquer apoio técnico e material que lhe for necessário (MINISTÉRIO DA EDUCAÇÃO, 2001).

Podemos dizer que tanto a Lei de Diretrizes e Bases da Educação Nacional (LDB) com o Plano Nacional de Educação (PNE) apontam medidas e ações inclusoras para o sistema de ensino, porém ainda são medidas generalizadoras que reduzem a complexidade de suas diversidades a um atrelamento médico - pedagógico.

A voz de muitos pesquisadores, da educação especial, traz uma preocupação quanto à descontinuidade da formação docente aos novos contextos inclusivos, expondo uma realidade que necessita ser priorizada dentro das políticas nacionais de educação inclusiva. A 
educação inclusiva, ainda, expressa contradições entre as leis que visam a sua regulamentação no ensino especial e a sua realidade. Além da estrutura curricular e da formação continuada do professor temos também que realizar o levantamento de todos os impedimentos que desfavorecem a inclusão escolar. A percepção do outro frente à condição da deficiência, também retratada pelo pesquisador Vita (2010), revela que os professores não tem capacitação como também tem um conhecimento pequeno frente às diferentes possibilidades de deficiência física/psíquica/mental.

A questão do currículo adaptado e da formação continuada do professor são condições para a efetividade da educação inclusiva, no entanto, Vita (2010), em seus estudos, detectou que apenas o Rio de Janeiro apresentava um currículo direcionado para as necessidades especiais.

VITA (2010) faz uma análise dos documentos de referência de todos os estados das regiões Sul, Sudeste e Centro-Oeste, três estados do Norte e seis do Nordeste e revelam dados interessantes a cerca da organização de serviços de Educação Especial nas diferentes regiões do Brasil. Esses documentos são unânimes em considerar que a oferta deveria ocorrer na Educação básica, incluindo a Educação Infantil, mas somente o Rio de Janeiro estabelecia orientações relativas à organização curricular e pedagógica diferenciada para os distintos níveis de ensino, destacando a importância da Educação Infantil para o processo de desenvolvimento e a possibilidade de menor rejeição ao processo inclusivo.

Os resultados do censo de 2006 oferecem dados gerais sobre as matrículas nas diferentes modalidades de ensino. Em relação à Educação Especial, restringem-se ao número total de matriculados (375.488), permitindo constatar uma variação negativa de $0,7 \%$ em relação a 2005 . Não há informações disponíveis sobre a inserção das crianças com necessidades especiais nas classes comuns das escolas regulares, tampouco é possível distingui-las pelo nível de formação: creche, pré-escola, ensino fundamental etc. (VITA, 2010, p.3). 
Segundo Carvalho (2005), o universo escolar da educação básica, historicamente marcado pela presença de um ensino repressor, encontra tanto na estrutura curricular, dos cursos docentes, como na formação continuada do professor, um descompasso frente às novas emergências da educação inclusiva.

O uso das tecnologias assistivas e de comunicação
alternativa acionou competências cognitivas,
organizacionais, sociais e comportamentais,
conquistando uma bem sucedida alfabetização, em uma
escola do ensino regular... [...] Os estudos
demonstraram que as atividades pedagógicas adaptadas
por meio de recursos CSA auxiliaram no processo de
ensino e aprendizagem do aluno. As principais
contribuições relatadas pela professora foram
direcionadas para o aumento da concentração, atenção,
memória, sequência lógica e iniciativa comunicativa de
modo contextualizado. Os recursos foram favorecedores
quanto ao entendimento e maior participação do aluno,
nas diferentes atividades pedagógicas (SAMESHIMA,
2009, p.40).

O que podemos dizer sobre educação infantil e as novas demandas para uma educação inclusiva aponta para uma realidade divergente daquela preconizada por leis e decretos, contudo a comunicação alternativa, aos poucos, permeia grupos de pesquisa e vem sendo implementada nas escolas com o sucesso de permitirem a comunicação não oral.

A discussão destinada às questões da Educação Inclusiva incorpora uma nova "bagagem teórica" que deve ampliar os horizontes conceituais, teóricos e práticos da Educação Infantil, ao possibilitar formas singulares de desenvolvimento entre as crianças. Neste sentido, a Comunicação Alternativa traz uma prática pedagógica para o desenvolvimento do processo linguístico da criança que não oraliza.

As novas construções epistemológicas do corpo-sujeito reconstroem a percepção da criança que aprende e encontra na Comunicação Alternativa uma proposta pedagógica que recoloca o foco do ensino e 
da aprendizagem para além da fala oral (ZOBOLI, 2009; CARVALHO, 2005).

A inclusão linguística, desde a Educação Básica, das crianças que não oralizam, leva em consideração que o desenvolvimento da fala oral não está diretamente relacionado à construção do pensamento e que a presença de uma linguagem interna pode superar a fala oral por meios não verbais expressando sentimentos e emoções ao construir um diálogo (FARIAS, 2009).

A Comunicação Alternativa traz uma nova prática pedagógica, trabalhando um sistema linguístico não oral, que possibilita a criança que não oraliza, a sua comunicação com o meio. Assim os sistemas de comunicação alternativa podem ser utilizados na escola com o intuito de possibilitar a interação e intensificar a comunicação da criança permitindo seu desenvolvimento e aprendizagem.

Os aspectos referentes à acessibilidade assegurada pela lei 10.098/2000 devem garantir as crianças que não oralizam a aquisição de recursos didático e pedagógicos e adaptações curriculares, bem como estão respaldados pelos artigos 208 e 227 da Constituição Federal que asseguram atendimento educacional especializado, acesso aos bens de serviço, eliminação dos preconceitos e obstáculos arquitetônicos.

A presença de um fonoaudiólogo, na escola, tem grande importância sendo um profissional que vem a realizar um conhecimento interdisciplinar com a pedagogia, lembrando que a presença do fonoaudiólogo nas escolas esta devidamente respaldada pela lei $6.965 / 1981$.

Quando fonoaudiólogos trabalham em conjunto com professores, eles trabalham direcionados na melhoria das competências de comunicação das crianças, na melhoria de acesso ao currículo, em maior autoestima dos professores, devido ao aumento da compreensão sobre o impacto das dificuldades de comunicação no ambiente escolar em maior conhecimento de como lidar com as dificuldades (SAMESHIMA, 2009, p.37).

Olh@res, Guarulhos, v. 3, n. 1, p. 122-142. Maio, 2015. 
Sameshima (2009), afirma que a comunicação alternativa também atinge objetivos como a expansão da comunicação, resultados positivos para a leitura, escrita e desenvolvimento da fala oral. Ainda como resultados práticos da comunicação alternativa, temos relatos de que as crianças que são submetidas a este sistema de comunicação apresentam melhoras no nível de atenção, memória e aspectos cognitivos da aprendizagem.

Para Sameshima (2009) a implementação de um sistema de Comunicação Alternativa, também preconizado por Deliberato (2009) pressupõe três etapas. Na primeira etapa a necessidade de orientações sistemáticas a respeito da linguagem e comunicação. Posteriormente apresentar os sistemas de CA e os vínculos entre comunicação, aprendizagem, leitura e escrita. Finalmente identificar o currículo escolar e conhecer o planejamento pedagógico da escola. A segunda etapa consiste na identificação das habilidades da criança e do estabelecimento da rotina da escola e a terceira etapa finaliza com a adaptação de materiais.

Os professores enfatizaram a importância do uso de sistemas de CSA para propiciar o desenvolvimento da linguagem e da linguagem escrita dos alunos com deficiência. Em sua avaliação as atividades pedagógicas adaptadas por meio dos sistemas de CSA possibilitam aos alunos o acesso, a participação e a realização das atividades do planejamento pedagógico. Perceberam que, mesmo não reconhecendo letras, palavras ou frases, os alunos podiam demonstrar suas capacidades de leitura escrita, como material adaptado e adequado as suas necessidades (SAMESHIMA, 2009, p.144).

A implementação de uma comunicação Alternativa pode acionar competências cognitivas, organizacionais, comunicativas, sociais possibilitando 0 processo de alfabetização. 


\section{Referências Bibliográficas:}

ALMEIDA, M. A.; PIZA, M. H. M.; LAMÔNICA, D. A. C. Adaptações do sistema de comunicação por troca de figuras no contexto escolar. Pró-Fono R. Atual. Cient. v.17 n.2 Barueri May/Aug. 2005.

ANDRADE, L. B. P. Educação infantil na trilha do direito. In: ANDRADE L. B. P. (orgs) Educação Infantil: Discurso, legislação e práticas institucionais. São Paulo: editora UNESP; São Paulo: Cultura Acadêmica, 2010.

AZENHA, C. A. O lugar do outro nas teorias sobre aquisição de linguagem. Int-Ação Rev. Fac. Educ UFG v.30, n.2, p.249-266. 2005.

BRASIL. Lei Darcy Ribeiro (1996). LDB: Lei de Diretrizes e Bases da Educação Nacional. 9ed. Brasília: Câmara dos Deputados, Edições Câmara, 2014.

BRASIL MINISTÉRIO DA EDUCAÇÃO. Diretrizes Nacionais Para Educação Básica. Secretaria de Educação Especial. MEC; SEESP, 2001.

CARNEVALE, L. B. et al. Comunicação Alternativa no contexto educacional: Conhecimento de professores. Rev. Bras. Educ. Espec. v.19 n.2 Marília Abr/June. 2013.

CARVALHO R. S. Educação Infantil: Práticas Escolares e o Disciplinamento dos Corpos. Dissertação de Mestrado Programa de Pós Graduação da Faculdade de Educação da Universidade Federal do Rio Grande do Sul, 2005.

CESA, C. C.; SOUZA A. P. R. Novas perspectivas em comunicação suplementar e/ou alternativa a partir da análise de periódicos internacionais. Rev. CEFAC. v.12 n.5 São Paulo Sept/Oct. 2010 .

CHUN, R. Y. S. Comunicação suplementar e/ou alternativa: abrangência e peculiaridades dos termos e conceitos em uso no Brasil. Pró-Fono Revista de Atualização Científica. v.2, n.1, p.69-74.jan/mar; 2009.

CROCHIK, J. L. et al. A análise de atitudes de professores do ensino fundamental no que se refere à educação inclusiva. Educ. Pesquisa. v.37 n.3 São Paulo set./dez. 2011.

CURY, C. R. J. A educação básica como direito. Cad. Pesquisa. v.38 n.134 São Paulo: maio/ago. 2008.

DELIBRATO, D. Uso de expressões orais durante a implementação do recurso de comunicação suplementar e alternativa. Rev. Bras. Educ. Espec. v.15 n.3 Marília Sept/Dec. 2009.

FARIAS I. R. et al. Reflexões sobre a inclusão linguística no contexto escolar. IN: DIAS F. et al (orgs). Educação Inclusiva a Deficiência e Contexto Social: Questões contemporâneas.

EDUFBA,

Salvador:

2009.

Olh@res, Guarulhos, v. 3, n. 1, p. 122-142. Maio, 2015. 
GATti, B. A.; BARreto, E. S. S.; ANDRÉ, Marli E. D. A. Políticas Docentes no Brasil. Um estado da Arte. Brasília UNESCO, 2011.

MORESCHI, C. L.; ALMEIDA, M. A. A comunicação alternativa como procedimento de desenvolvimento de habilidades comunicativas. Rev. Bras. Educ. Espec. v.18 n.4 Marília Oct/Dec. 2012.

PAULA, K. M.; ENUMO, S. R. F. Avaliação assistida e comunicação alternativa: Procedimentos para a educação inclusiva. Rev. Bras. Educ. Espec. v.13 n.1 Marília jan./abr. 2007.

PEREIRA, C. L. Piaget, Vygotsky e Wallon: Contribuições para os estudos da linguagem. Psicol. Estud. v.17 n.2 Maringá abr/jun. 2012.

PIMENTEL, S. C. Formação de professores para inclusão. Saberes Necessários e percurso formativo. In: MIRANDA, T. G.; GALVÃO FILHO,T. A. (orgs). O Professor e a Educação Inclusiva: Formação, prática e lugares. Salvador; EDU FBA, 2012.

SAMESHIMA Fabiana Sayuri. Capacitação de Professores no Contexto de Sistemas de Comunicação Suplementar e Alternativa. Tese de doutorado Programa de Pós Graduação em educação da Faculdade de Filosofia e Ciências - UNESP. 2009

SCHEIB, L. Valorização e formação de professores para a educação básica: questões desafiadoras para um novo plano nacional de educação. Rev. Educ. Soc. v.31, n.112, Campinas: jul/set 2010.

SEKKEL, M. C.; MATOS, L. P. Educação inclusiva: formação de atitudes na educação infantil. Psicol. Esc. Educ. v.18 n.1 Maringá jan/jun. 2011.

VITA, F. C. F. A inclusão da criança com necessidades especiais na visão de berçaristas. Cad. Pesquisa. v.40, n.139, São Paulo: jan/abr. 2010.

VON TETZCHNER, S. et al. Inclusão de crianças em educação pré-escolar regular utilizando comunicação suplementar e alternativa. Rev. Bras. Educ. Espec. v.11 n.2 Marília May/Aug. 2005.

ZOBOLI, F. et al. Corpo e Alteridade nos Complexos e (IN) Exclusão. In: DIAS FELIZ et al.(orgs). Educação Inclusiva a Deficiência e Contexto Social: Questões contemporâneas. EDUFBA, Salvador: 2009.

ZUCCHETTI, D. T. A inclusão escolar vista sob a ótica de professores da educação básica. Educ. Rev. v.27 n.2 Belo Horizonte ago. 2011.

Recebido para publicação em 14 de fevereiro de 2015 Aprovado em 02 de abril de 2015

Olh@res, Guarulhos, v. 3, n. 1, p. 122-142. Maio, 2015. 